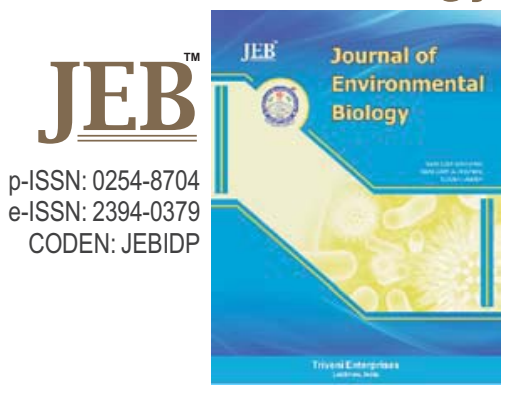

\title{
Seasonal variation of copepod community structure in Chavara coast along the Southern Kerala, India
}

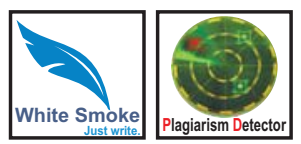

\section{Authors Info}

Jemi Job N.* and A. A. M. Hatha

Department of Marine Biology, Microbiology and Biochemistry, School of Marine Sciences, Cochin University of Science and Technology, Cochin-682 016, India

${ }^{*}$ Corresponding Author Email : jemicheeran@gmail.com
Key words

Copepod abundance

Chavara coast

Hydrographical parameters

Multivariate analysis

Zooplankton abundance

Publication Info

Paper received : 02.11 .2016

Revised received: 08.03.2017

Re-revised received : 26.06 .2017

Accepted:08.08.2017

\section{Abstract}

Aim : To analyze whether the seasonally differing hydrographical parameters can alter chlorophyll a and zooplankton community distribution in Chavara coast during two different seasons.

Methodology : The samples were collected from $10 \mathrm{~m}$ and $30 \mathrm{~m}$ locations from Chavara during November 2013 (Northeast Monsoon), May 2014 (Spring Intermonsoon). The collected zooplankton samples were analyzed in a stereo zoom microscope and copepods were identified to the species level. The relation between environmental parameters and zooplankton abundance was examined using statistical tools.

Results : Water column was cool, nutrient rich and less oxygenated (subsurface) during November. Water column was characterized as warm, high saline and with less nutrients during May. These variations were closely linked with the increased cooling and continuation of weakened upwelling during November. Chlorophyll a was found two to five folds higher during northeast monsoon compared to the spring intermonsoon. Overall, 14 zooplankton groups were recorded in the present study of which copepods contributed more than $70 \%$ to the total zooplankton density. Zooplankton (3619.5 No.m-3) and copepod abundance (3212.8 No.m-3) was high in November. Non-metric Multidimensional Scaling (NMDS), Agglomerative Hierarchical Cluster Analysis (AHCA) on Bray-Curtis similarity clearly separated the samples of two clusters $(30 \mathrm{~m}$ and $10 \mathrm{~m}$ ) in two different seasons.

Interpretation: The copepods showed more similarity within season and more heterogeneity between two seasons. Some copepod species showed positive relationship with the environmental variables.
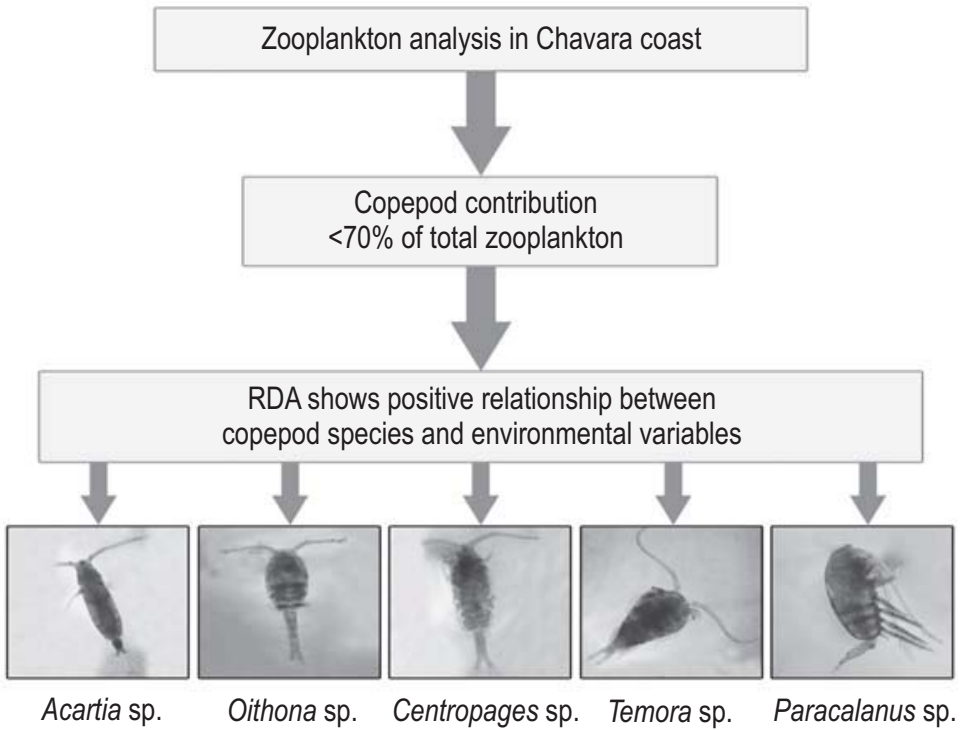


\section{Introduction}

The zooplankton often constitutes a substantial component of the plankton community in marine environments (Kane 2007; Keister et al., 2012). Copepods, the predominant taxon in mesozooplankton community support the transfer of nutrient and energy from phytoplankton and bacteria to higher trophic levels in marine pelagic food webs (Kobari et al., 2008; Abe et al., 2013). Copepods are sensitive to water mass properties, which are the important factors that affect their spatial distribution and abundance (Hwang and Wong, 2005; Hwang et al., 2006). This implies that some copepod species can be used as biological indicators of various water masses (Hwang et al., 2006; Hwang et al., 2007). Copepods show spatial and temporal variations in their distribution patterns (Hsiao et al., 2011; Naz et al., 2012; Balqis et al., 2016).

Temporal changes in distribution and abundance of zooplankton may be caused by variations of many abiotic and biotic factors. Planktonic copepods are strongly related to the hydrographic characteristics of marine environment. Hydrographical parameters between the seasons showed significant differences in southwest coast of India related to various physical processes like upwelling, riverine influx and summer stratification etc. (Madhupratap et al., 1996; Jyothibabu et al., 2008). Chavara coast is a specialized ecosystem due to the formation of frequent occurrence of mud bank and one of the major fishing sites of southwest coast of India. Coastal waters of Chavara has been subjected to pollution due to discharge from the titanium dioxide producing industry and the sewage discharge also causes severe damage to the fishery resources of this region. This region is world famous for its rich heavy mineral resources like rutile and ilmenite. Seasonal variation of copepod community structure was studied by different authors in different regions of India (Perumal et al., 2009; Santhanam et al., 2012; Stephen et al., 2013; Sanu et al., 2014). However, the information on zooplankton and copepod species diversity from the coastal waters of Southern Kerala (Robin et al., 2009; Jeyaraj et al., 2014; Vineetha et al., 2015; Cleetus et al., 2016) is still sparse. The studies on copepod dynamics from Chavara were limited to the observations of Robin et al. (2009). Hence, the present study was undertaken in Chavara coast along the Southern Kerala to study the influence of hydrography on zooplankton distribution and copepod species diversity during two different seasons.

\section{Materials and Methods}

The southwest coast of India is an important stretch of coastline having richer marine fauna and flora. Seasonally reversing monsoons is a characteristic feature of southwest coast of India. Two locations along Chavara transect, which at $10 \mathrm{~m}$ location - latitude $9^{\circ} 00^{\prime} 044^{\prime \prime} \mathrm{N}$ and $76^{\circ} 29^{\prime} 454^{\prime \prime} \mathrm{E}$ longitude; $30 \mathrm{~m}$ location - latitude $9^{\circ} 00^{\prime} 0411^{\prime \prime} \mathrm{N}$ and $76^{\circ} 21^{\prime} 615^{\prime \prime} E$ longitude were selected for the study (Fig. 1). The Chavara coast which covers coastal stretch of $22 \mathrm{~km}$ length from Neendakara to Kayamkulam is world famous for its rich heavy mineral resources. Sampling was carried out in northeast monsoon and spring intermonsoon. At each location, water samples were collected from surface, middle ( $5 \mathrm{~m}$ in $10 \mathrm{~m}$ location and $15 \mathrm{~m}$ in $30 \mathrm{~m}$ location) and bottom (9 $\mathrm{m}$ in $10 \mathrm{~m}$ location and $28 \mathrm{~m}$ in $30 \mathrm{~m}$ location) using 5 I Niskin sampler (General Oceanics, USA) for measuring chlorophyll a, dissolved oxygen and nutrients. The vertical distribution of physical parameters such as salinity and temperature were recorded by factory calibrated sensors. Nitrate was measured by Grasshoff's method (Grasshoff et al., 1983). The dissolved oxygen was estimated by Winkler's modified method (Grasshoff et al., 1983) and the extracted chlorophyll a was measured by a Trilogy Turner fluorometer following the standard procedure (UNESCO, 1994).

Zooplankton samples were collected by horizontal hauls using WP-2 net (200 $\mu \mathrm{m}$ mesh size), attached with a calibrated digital flow meter (Hydro-bios, Germany). After each haul the zooplankton sample was transferred into clean 0.5 I plastic containers and the samples were fixed in $(4-5 \%)$ buffered formalin. Zooplankton sub-samples $(25 \%)$ were sorted and analyzed in a stereo zoom microscope (Model - Motic DMW 143 - FBGG) and taxonomic group level abundance was estimated (Postel et al., 2000). Among various taxonomic groups, copepods were further analyzed and identified to the species level using standard keys (Kasturirangan, 1963; Conway et al., 2003). The zooplankton diversity was represented using three common diversity indices - species diversity index $\left(\mathrm{H}^{\prime}\right)$, species richness (d), evenness index ( $\mathrm{J}^{\prime}$ ) and were calculated by using the formulas of Shannon Wiener (1963), Margalef (1968) and Pielou (1969) respectively. In order to study the spatial and seasonal variation in environmental and biological parameters in Southwest coast of India (Chavara) parametric ANOVA was carried out on data having normal distribution. The tests of normality, parametric and nonparametric ANOVA were carried out in XL stat pro - software package.

Multivariate analysis was used to understand the relationship among the physicochemical, mesozooplankton communities and copepod orders (PRIMER 6). Hierarchical agglomerative method of cluster analysis was used to segregate different sampling locations based on their environmental and biological parameters. The results were represented by a dendrogram with $x$-axis representing the full set of stations and $y$ axis defining the similarity level at which the samples or groups were fused (Jagadeesan et al., 2013). Cluster analysis followed by Non-metric multidimensional scaling plots (NMDS) was used to segregate locations with similar properties. Copepod species abundance data were initially $\log (X+1)$ transformed to normalize the differences in numerical abundance (Clarke and Warwick, 2001). The spatial grouping of locations in different seasonal collections was done by the Bray - Curtis similarity matrix using group average method. To identify significant assemblages of stations $(p<0.01)$ similarity profile (SIMPROF) permutation test was also performed (Clarke and Gorley, 2006). The relationships between important species of copepods and environmental variables were analyzed using RDA (CANOCO 4.5). The biological variables were log transformed and centered prior to the analysis. Monte Carlo permutation tests (499 unrestricted 
permutations) $(p<0.05)$ was used to test the ordination significance. The samples were displayed by points and species and quantitative environmental variables were shown by arrows in triplots of RDA.

\section{Results and Discussion}

Seasonal changes in waves and currents are experienced by the monsoon dominated coast, Chavara in Southwest coast of India (Hameed et al., 2007). The general current pattern explains the stronger southerly currents during monsoon and weaker northerly currents during fair weather in Chavara. Northeast monsoon period was reported as weak and moderate upwelling season near the southwest coast (between $8^{\circ} \mathrm{N}$ and $14^{\circ} \mathrm{N}$ latitudes) in the study of Smitha et al. (2014). The hydrographical changes may influence the biological factors in coastal waters of Chavara. Salinity ranged from 33.26 ppt to $35.52 \mathrm{ppt}$ in the present observations (Table 1). Salinity did not show much variation between the collections during May and November (ANOVA, $P>0.05$ ). During May (spring intermonsoon), surface salinity was high compared to November, whereas in the bottom salinity was high during November. The high salinity of water during May (spring intermonsoon period) is the normal nature of the Arabian Sea (Shenoi et al., 2005) and the salinity of the coastal waters may go down due to riverine inputs from the adjacent areas and littoral inputs from small canals. During the northeast monsoon period the coastal water salinity becomes intermediate between the spring intermonsoon and southwest monsoon period, this observations were in accordance with the earlier observations like Madhuparatap et al. (1990), Madhuparatap et al. (2001) from the south easternArabian Sea.

Table 1 : Distribution of physico chemical parameters and chlorophyll a in Chavara during November 2013 and May 2014

\begin{tabular}{|c|c|c|c|c|c|}
\hline \multirow{2}{*}{ Parameters } & \multirow{2}{*}{ Depth } & \multicolumn{2}{|c|}{ November } & \multicolumn{2}{|c|}{ May } \\
\hline & & $10 \mathrm{~m}$ & $30 \mathrm{~m}$ & $10 \mathrm{~m}$ & $30 \mathrm{~m}$ \\
\hline \multirow{3}{*}{ Salinity (ppt) } & $S$ & 33.26 & 34.35 & 34.65 & 35.52 \\
\hline & $M$ & 34.1 & 34.39 & 34.81 & 34.8 \\
\hline & $B$ & 35.12 & 35.16 & 34.91 & 34.98 \\
\hline \multirow{4}{*}{ Temperature $\left({ }^{\circ} \mathrm{C}\right)$} & $S$ & 26.3 & 26.4 & 31.5 & 30.9 \\
\hline & $M$ & 25.6 & 25.2 & 30.1 & 30.3 \\
\hline & $B$ & 24.8 & 24.3 & 29.8 & 29.7 \\
\hline & $S$ & 5.74 & 5.15 & 5.6 & 5.05 \\
\hline \multirow[t]{2}{*}{$\mathrm{DO}\left(\mathrm{mg} \mathrm{l}^{-1}\right)$} & M & 4.89 & 4.89 & 5.12 & 4.98 \\
\hline & $B$ & 3.15 & 3.05 & 5.05 & 4.85 \\
\hline \multirow{4}{*}{ Nitrate $(\mu \mathrm{M})$} & $S$ & 3.69 & 5.91 & 0.14 & 0.11 \\
\hline & $M$ & 2.65 & 4.95 & 0.32 & 0.19 \\
\hline & $B$ & 3.56 & 3.25 & 0.46 & 0.25 \\
\hline & $S$ & 4 & 5.96 & 1.3 & 0.4 \\
\hline \multirow{2}{*}{$\begin{array}{l}\text { Chlorophyll a } \\
\left(\mathrm{mg} \mathrm{m}^{-3}\right)\end{array}$} & $M$ & 3.12 & 3.19 & 0.89 & 0.65 \\
\hline & $B$ & 3.09 & 3.18 & 1.1 & 0.98 \\
\hline
\end{tabular}

S- Surface, M - Middle and B - Bottom
The spatial distribution of the temperature showed minor differences $\left(<0.5^{\circ} \mathrm{C}\right)$, but the temporal distribution of the temperature showed $\sim 5^{\circ} \mathrm{C}$ variations (Table 1) between November and May. Water column was warmer during May compared to November. In May, dissolved oxygen was found $5.0 \mathrm{mg} \mathrm{l}^{-1}$ in surface, middle and bottom layers of $10 \mathrm{~m}$ and $30 \mathrm{~m}$ locations. During November, surface DO was $>5.0 \mathrm{mg} \mathrm{l}^{-1}$, but in bottom layers DO concentrations was low and found $\sim 3.2 \mathrm{mg} \mathrm{l}^{-1}$ at $10 \mathrm{~m}$ and $30 \mathrm{~m}$ locations respectively. In the month of November it was found $5.74 \mathrm{mg} \mathrm{l}^{-1}$ and $5.15 \mathrm{mg} \mathrm{l}^{-1}$ in $10 \mathrm{~m}$ and 30 $\mathrm{m}$ locations respectively. The highest concentration of dissolved oxygen was recorded during the northeast monsoon (November). Nitrate showed noticeable differences between May and November (ANOVA, P<0.05) in all three layers. The warm waters and fewer nutrients during the spring intermonsoon period represent the oligotrophic nature of the Arabian Sea (Wiggert et al., 2005). Similar kinds of observations, like low concentrations of nitrate, warmer water temperature and oligotrophic nature during the spring intermonsoon period was reported by Madhupratap et al. (1990, 1996), Smith et al. (1998) and Sarangi et al. (2011). The low concentrations of nitrate, warm temperature and high salinity were found during May than November. This represents the oligotrophic or low productivity in Chavara station during spring intermonsoon in the present study.

In general, nitrate concentration was two to five folds high during November compared to May (Table 1). During May, nitrate was found $<1 \mu \mathrm{M}$ and in November it was $>3 \mu \mathrm{M}$. The high concentrations of nitrate and less sea surface temperature during

Table 2 : Zooplankton groupwise abundance (No. $\mathrm{m}^{-3}$ ) in the two different seasonal collections in Chavara transect during November 2013 and May 2014

\begin{tabular}{lllll}
\hline \multirow{2}{*}{ Groups } & \multicolumn{2}{l}{ November } & \multicolumn{3}{l}{ May } \\
\cline { 2 - 5 } & $\mathbf{1 0} \mathrm{m}$ & $\mathbf{3 0 ~} \mathrm{m}$ & $\mathbf{1 0 ~ \mathrm { m }}$ & $\mathbf{3 0 ~ \mathrm { m }}$ \\
\hline Medusae & 1.3 & 2.1 & - & - \\
Siphonophores & 2.6 & 0.6 & 3.2 & 1.6 \\
Chaetognaths & 65.3 & 72.3 & 204.8 & 70.4 \\
Copepods & 3212.8 & 1510.4 & 1003.2 & 406.4 \\
Cladocerans & 235.2 & 222.2 & 98.4 & 20.8 \\
Amphipods & - & - & 1.6 & - \\
Appendicularians & 21.1 & 9.1 & 22.4 & 11.2 \\
Lucifer & 7 & 0.6 & 1.6 & 1.6 \\
Mysid & 6.4 & - & 1.6 & 1.6 \\
Thalacians & - & - & 1.6 & 1.6 \\
Decapod larvae & 49.9 & 0.3 & 64 & 3.2 \\
Molluscan larvae & - & 5.1 & 1.6 & 8 \\
Fish eggs & 17.9 & 35.5 & 12.8 & - \\
Fish larvae & - & - & 8 & - \\
Total & 3619.5 & 1858.2 & 1424.8 & 526.4 \\
\hline
\end{tabular}

(0 - denotes absence) 
Table 3 : Spatial distribution of copepod species in the two different seasonal collections in Chavara transect during November 2013 and May 2014

\begin{tabular}{|c|c|c|c|c|c|c|c|c|c|}
\hline \multirow{2}{*}{ Groups } & \multicolumn{2}{|l|}{ Nov } & \multicolumn{2}{|l|}{ May } & \multirow{2}{*}{ Groups } & \multicolumn{2}{|l|}{ Nov } & \multicolumn{2}{|l|}{ May } \\
\hline & $10 \mathrm{~m}$ & $30 \mathrm{~m}$ & $10 \mathrm{~m}$ & $30 \mathrm{~m}$ & & $10 \mathrm{~m}$ & $30 \mathrm{~m}$ & $10 \mathrm{~m}$ & $30 \mathrm{~m}$ \\
\hline Medusae & 1.3 & 2.1 & - & - & Labidocera pectinata & + & ++ & * & ++ \\
\hline Undinula vulgaris & ++ & ++ & + & + & Labidocera minuta & - & + & - & + \\
\hline Rhincalanus cornutus & - & ++ & - & - & Pontellopsis macronyx & - & + & + & - \\
\hline Rhincalanus nasutus & - & +++ & - & - & Pontellina plumata & - & ++ & + & - \\
\hline Pareucalanus elongatus & + & +++ & + & - & Acartia erythraea & ++ & +++ & ++ & ++ \\
\hline Pareucalanus attenuatus & ++ & ++ & ++ & + & Acartia danae & +++ & $* *$ & ++ & + \\
\hline Paracalanus parvus & $* * *$ & $* *$ & * & ++ & Macrosetella gracilis & ++ & ++ & + & + \\
\hline Acrocalanus gibber & ++ & ++ & ++ & + & Euterpina acutifrons & +++ & - & + & - \\
\hline Acrocalanus gracilis & ++++ & t++ & ++ & + & Oithona spinirostris & +++ & - & - & + \\
\hline Centropages orsini & $* * *$ & ++++ & ++ & ++ & Oithona plumifera & ++ & - & + & + \\
\hline $\begin{array}{l}\text { Centropages furcatus } \\
\text { Centropages tenuiremis }\end{array}$ & $\begin{array}{l}- \\
*\end{array}$ & $\begin{array}{l}- \\
-\end{array}$ & $\begin{array}{l}++ \\
++\end{array}$ & $\begin{array}{l}- \\
++\end{array}$ & Oithona rigida & ++ & - & ++ & + \\
\hline Pseudodiaptomus aurivilli & - & - & + & - & Oithona brevicornis & - & - & + & - \\
\hline Pseudodiaptomus serricaudatus & + & + & + & - & Oithona similis & ++++ & - & + & + \\
\hline Temora turbinata & $* * *$ & ++ & ++ & + & Oncaea venusta & +++ & ++ & + & + \\
\hline Temora stylifera & - & ++ & ++ & + & Corycaeus speciosus & ++ & ++ & ++ & ++ \\
\hline Temora discaudata & - & + & + & - & Corycaeus danae & + & - & ++ & - \\
\hline Candacia discaudata & - & ++ & - & - & Corycaeus catus & ++ & +++ & +++ & +++ \\
\hline Candacia bradyi & ++ & - & - & - & Corycella gibbula & - & - & - & + \\
\hline Calanopia minor & - & - & - & + & Sapphirina ovatolanceolata & - & - & - & + \\
\hline Labidocera acuta & + & + & ++ & +++ & Monstrilloids & ++ & ++ & - & - \\
\hline
\end{tabular}

denotes copepods density $>0.1$ to $\leq 10$; ++ denotes 10.1 to $\leq 50$; +++ denotes 50.1 to $\leq 100 ;++++$ denotes 100.1 to $\leq 200$; ${ }^{*}$ denotes 200.1 to $\leq$ $300 ;{ }^{* *}$ denotes 300.1 and $\leq 400 ;{ }^{* * *}$ denotes 400.1 to $\leq 500 ; 0$ denotes absence

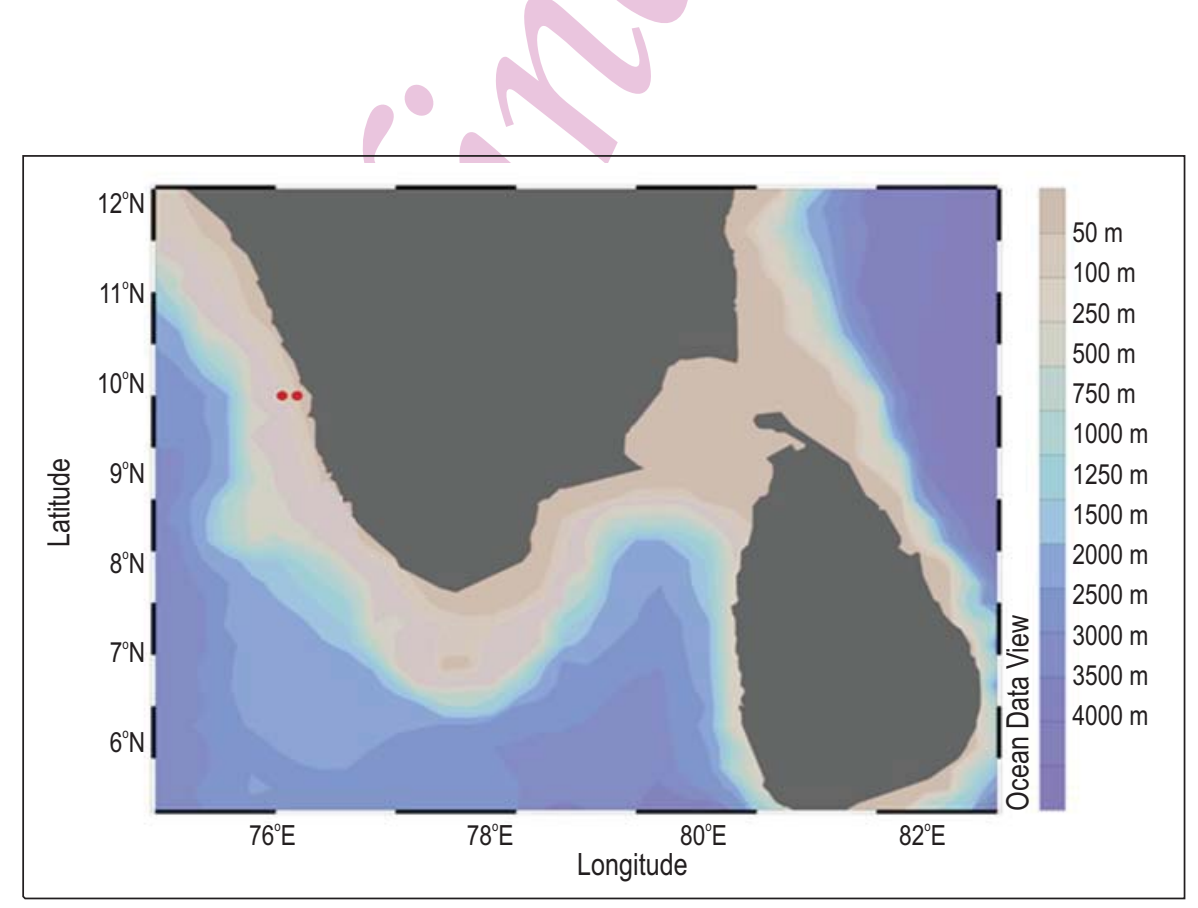

Fig .1 : Map showing the geographical locations of the sampling stations 


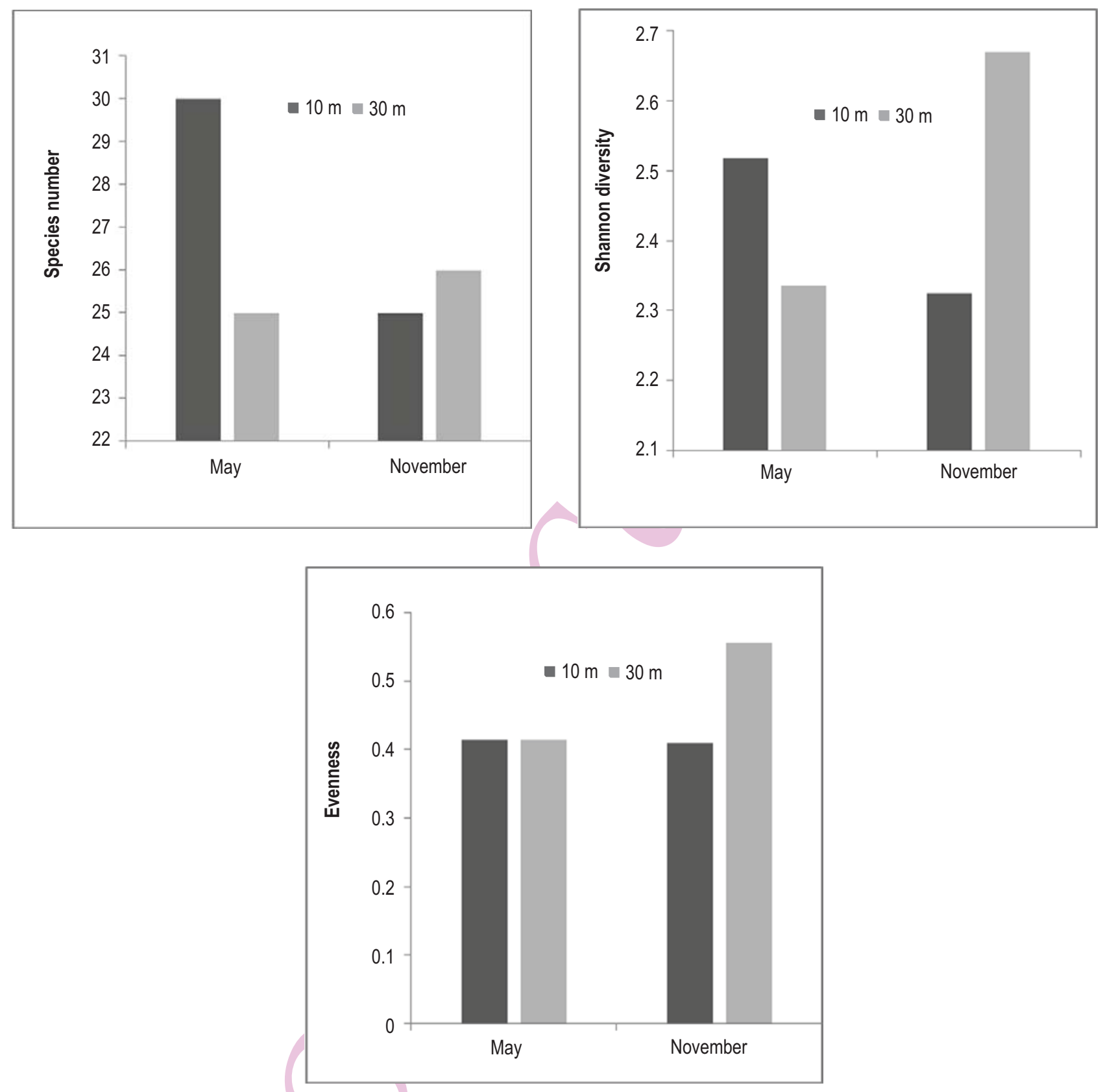

Fig. 2 : Diversity indices of copepod community structure in two different seasonal collections from the Chavara transect during November 2013 and May 2014 (a) Species richness (b) Shannon diversity and (c) Pielous evenness

the northeast monsoon period in the Arabian Sea are the result of the winter cooling (Saher et al., 2007; Gerson et al., 2014). Chlorophyll $a$ is considered as the representation of the phytoplankton biomass and production. In the present study the high chlorophyll a concentrations during November (Northeast Monsoon) from the Chavara transect as the result of the winter cooling and weakened upwelling. The differences in nutrients influenced the Chlorophyll a distribution in the study area. The temporal distribution of Chlorophyll a showed the significant differences (ANOVA, $P<0.05$ ). Chlorophyll a concentrations ranged from 0.40 to $1.30 \mathrm{mg} . \mathrm{m}^{-3}$ in May and 3.09 to $5.96 \mathrm{mg} . \mathrm{m}^{-3}$ in November (Table 1). The maximum chlorophyll a concentration was found during November and it was less during May.

Zooplankton abundance ranged from $526.4 \mathrm{No}^{-3}$ to 3619.5 No. $^{-3}$ (Table 2) and showed remarkable seasonal pattern in the present study. High zooplankton abundances during November (two folds higher) and the lowest zooplankton production during May were found in Chavara station. In altogether, 14 zooplankton groups were reported in 
Table 4 : Results of SIMPER analysis represent the similarity within and between the clusters in Chavara transect during November 2013 and May 2014

(a) Group 1 members (the stations of $10 \mathrm{~m}$ and $30 \mathrm{~m}$ during May) showed the $47.42 \%$ similarity within observations

\begin{tabular}{lllll}
\hline Species & $\begin{array}{l}\text { Av. } \\
\text { Abund }\end{array}$ & $\begin{array}{l}\text { Av. } \\
\text { Sim }\end{array}$ & Contrib\% & Cum.\% \\
\hline Labidocera pectinata & 146.24 & 15.53 & 32.76 & 32.76 \\
Centropages orsini & 55.75 & 10.86 & 22.91 & 55.67 \\
Labidocera acuta & 61.33 & 5.97 & 12.59 & 68.26 \\
Paracalanus parvus & 118.28 & 4.6 & 9.69 & 77.95 \\
Acartia erythraea & 19.95 & 3.9 & 8.23 & 86.18 \\
Centropages tenuiremis & 18.79 & 2.14 & 4.52 & 90.7 \\
\hline
\end{tabular}

(b) Group 2 members (the stations of $10 \mathrm{~m}$ and $30 \mathrm{~m}$ during November) showed the $60.32 \%$ similarity within observations

\begin{tabular}{|c|c|c|c|c|}
\hline Species & $\begin{array}{l}\text { Av. } \\
\text { Abund }\end{array}$ & $\begin{array}{l}\text { Av. } \\
\text { Sim }\end{array}$ & Contrib\% & Cum. $\%$ \\
\hline Paracalanus parvus & 654.23 & 13.68 & 22.68 & 22.68 \\
\hline Centropages tenuiremis & 262.72 & 10.83 & 17.95 & 40.63 \\
\hline Centropages orsini & 274.17 & 6.84 & 11.34 & 51.97 \\
\hline Acartia danae & 182.29 & 5.9 & 9.78 & 61.75 \\
\hline Acrocalanus gracilis & 135.68 & 5.67 & 9.4 & 71.15 \\
\hline Oithona similis & 113.63 & 4.76 & 7.9 & 79.04 \\
\hline Oithona spinirostris & 90.6 & 3.63 & 6.02 & 85.06 \\
\hline Acartia erythraea & 60.5 & 2.04 & 3.38 & 88.44 \\
\hline Pareucalanus attenuatus & 54.53 & 1.81 & 3.01 & 91.45 \\
\hline
\end{tabular}

\begin{tabular}{|c|c|c|c|c|c|c|}
\hline 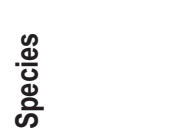 & 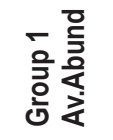 & 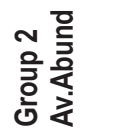 & $\begin{array}{l}\frac{.00}{0} \\
\frac{0}{\dot{\alpha}}\end{array}$ & $\begin{array}{l}\frac{\text { OD }}{\text { D. }} \\
\stackrel{0}{0}\end{array}$ & 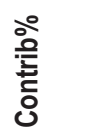 & 宅 \\
\hline $\begin{array}{l}\text { Paracalanus } \\
\text { parvus }\end{array}$ & 118.28 & 654.23 & 17.66 & 1.66 & 22.82 & 22.82 \\
\hline $\begin{array}{l}\text { Centropages } \\
\text { tenuiremis }\end{array}$ & 18.79 & 262.72 & 9.28 & 4.46 & 11.99 & 34.81 \\
\hline $\begin{array}{l}\text { Temora } \\
\text { turbinata }\end{array}$ & & 294.25 & 8.35 & 0.94 & 10.8 & 45.61 \\
\hline $\begin{array}{l}\text { Centropages } \\
\text { orsini }\end{array}$ & 55.75 & 274.17 & 7.3 & 2.56 & 9.43 & 55.04 \\
\hline $\begin{array}{l}\text { Acartia } \\
\text { danae }\end{array}$ & 30.79 & 182.29 & 6.4 & 1.51 & 8.28 & 63.32 \\
\hline $\begin{array}{l}\text { Acrocalanus } \\
\text { gracilis }\end{array}$ & 6.93 & 135.68 & 5.06 & 2.73 & 6.55 & 69.87 \\
\hline $\begin{array}{l}\text { Labidocera } \\
\text { pectinata }\end{array}$ & 146.24 & 10.16 & 4.99 & 1.68 & 6.45 & 76.32 \\
\hline $\begin{array}{l}\text { Oithona } \\
\text { similis }\end{array}$ & 1.43 & 113.63 & 4.3 & 3.88 & 5.56 & 81.87 \\
\hline $\begin{array}{l}\text { Oithona } \\
\text { spinirostris }\end{array}$ & 0.23 & 90.6 & 3.58 & 2.52 & 4.63 & 86.5 \\
\hline $\begin{array}{l}\text { Labidocera } \\
\text { acuta }\end{array}$ & 61.33 & 8.55 & 2.15 & 1.19 & 2.78 & 89.28 \\
\hline $\begin{array}{l}\text { Pareucalanus } \\
\text { attenuatus }\end{array}$ & 2.59 & 54.53 & 2.15 & 1.77 & 2.77 & 92 \\
\hline
\end{tabular}

Av. Abund: Average abundance, Av.Sim: Average similarity, Contrib\%: Contribution percentage, Cum. \%: Cumulative percentage, Av. Diss: Average dissimilarity, Diss/SD: Dissimilarity/Standard Deviation

the present study (Table 2), copepods contributed more than $70 \%$ to the total density. Copepods contribution to total density was high in the month of November at depth. $10 \mathrm{~m}$. In January collection at $10 \mathrm{~m}$ depth chaetognaths contributed $13-14 \%$ of zooplankton, while in November their contribution reduced to less than $10 \%$. Decapod larvae contributed $4.4 \%$ to the total density in the month of May at the depth of $10 \mathrm{~m}$, whereas at other stations their contributions never exceeded more than $2 \%$. Cladocerans distribution showed clear seasonality; in May their contribution was found to be $6.6 \%$ and $3.95 \%$ in $10 \mathrm{~m}$ and $30 \mathrm{~m}$ locations, respectively. But in the month of November their contribution was found $11 \%$ at $30 \mathrm{~m}$ and $10 \mathrm{~m}$ locations. Fish eggs density was high in November as compared to May. Similar observations about seasonal variations of zooplankton production between the seasons were reported from southwest coast of India (Rajagopalan et al., 1992; Rao et al., 1992). In the present study, the copepods are the most dominant zooplankton groups. Similar kinds of observations about the dominance of copepods to the total density were reported by Perumal et al. (2009), Fernandes and Ramaiah (2009), Jagadeesan et al. (2013) and Jayaraj et al. (2014).
Copepods density ranged between $406.4 \mathrm{No}^{-3}$ to $3212.8 \mathrm{No}^{-3} \mathrm{~m}^{3}$ and it was higher in the month of November. The minimum copepods density 406.4 No. $\mathrm{m}^{-3}$ was reported in May at the depth of $30 \mathrm{~m}$. b) In the present study, altogether 40 species were reported, among these, 26 belong to the order Calanoida, 2 belonged to order Harpacticoida, 5 species belonged to Cyclopoida order and 7 species belonged to the order Poecillostomatoida. In Calanoida order, 9 families were found such as Calanidae, Eucalanidae, Paracalanidae, Centropagidae, Pseudodiaptomidae, Temoridae, Candaciidae, Pontellidae, Acartiidae. In Harpacticoida order, 2 families naming, Macrosetellidae, Tachidiidae were found. Copepod species richness was high in May at $10 \mathrm{~m}$ coastal locations. Species richness was comparable at $30 \mathrm{~m}$ location of May and $10 \mathrm{~m}$ location of November. Individual species distribution showed remarkable temporal variations. The individual species density and their distribution were shown in Table 3. Shannon diversity was high during May at $10 \mathrm{~m}$ locations while in November it was high at $30 \mathrm{~m}$ locations. Pielous evenness was high at $30 \mathrm{~m}$ locations compared to the $10 \mathrm{~m}$ locations in November (Fig. 2). The phytoplankton size, predator availability, toxic substances, dissolved gases, quality and quantity of the food materials available from their surroundings 


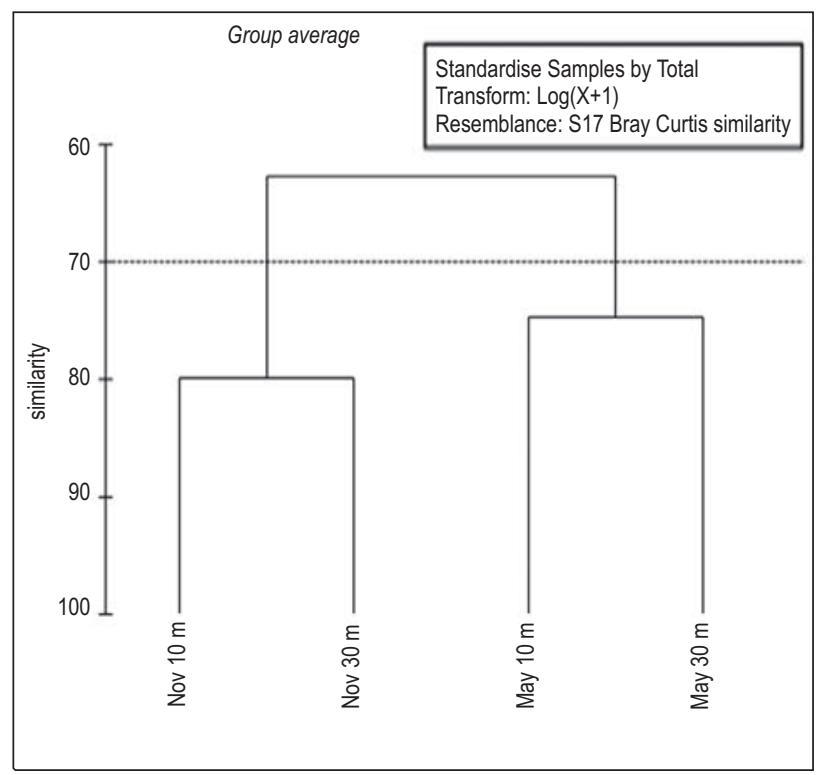

Fig. 3 : Bray - Curtis similarity index based group average liknage dendrogram of cluster analysis from Chavara transect

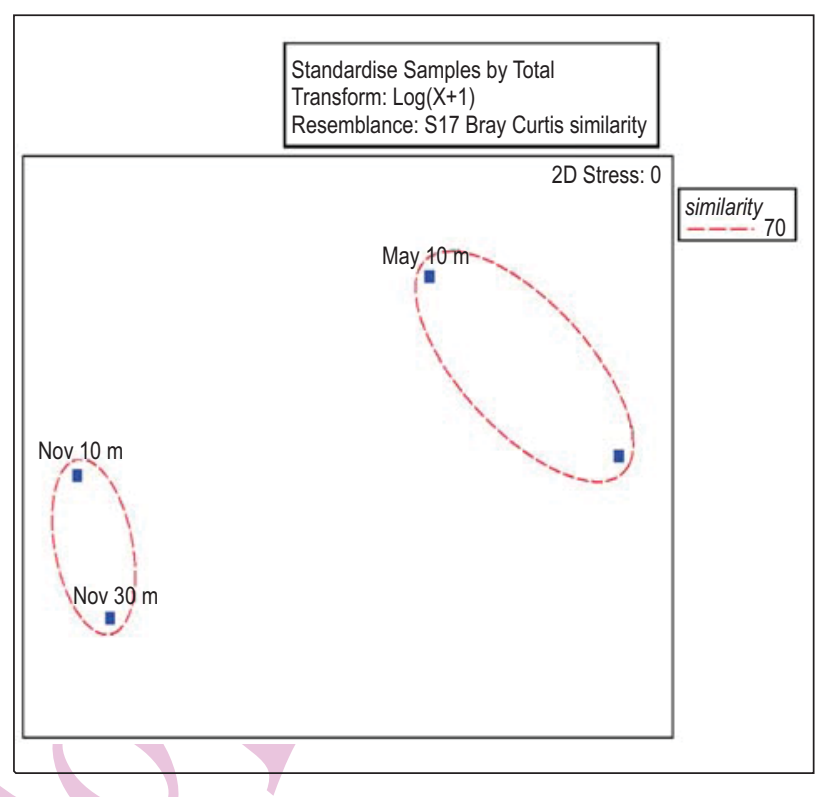

Fig. 4 : Cluster overlaid two dimensional NMDS plot visualizes the spatial assemblages of the locations and observations based on their relatedness to the dominant copepod species distribution in Chavara

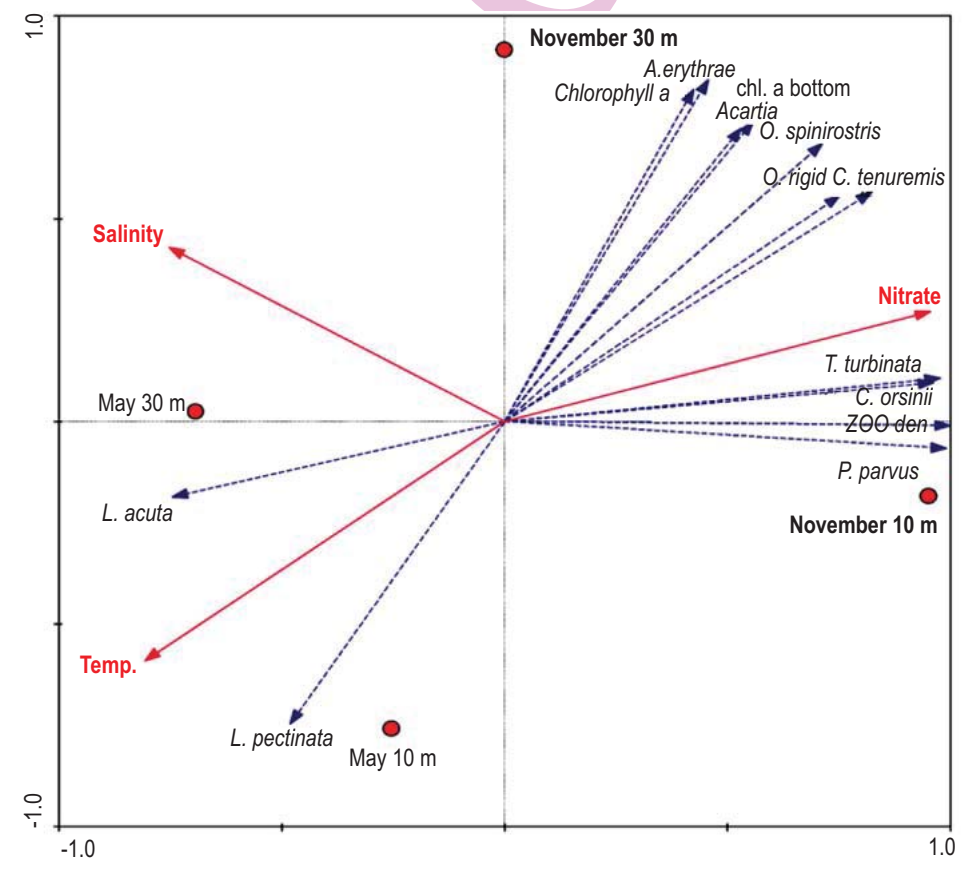

Fig. 5 : RDA triplot visualizes inter relationships within and between the biological and environmental variables in Chavara transect

influence the distribution of copepods (Jagadeesan et al., 2013). During the Spring Intermonsoon period May and later Southwest Monsoon period showed differences in the copepod species distribution, especially that of the Temora turbinata, Oithona similis, Centropages orsini, Paracalanus parvus, Centropages tenuiremis, Corycaeus catus and Acartia erythraea were significantly differed.
The abundance of the Temora turbinata was found to be higher during the Northeast Monsoon period. These kinds of the seasonal pattern in the copepod species distribution was reported from the Indian waters (Madhupratap et al., 1990; Gowsami and Padmavati, 1996; Madhuparatp et al., 2001; Rakesh et al., 2006; Rakesh et al., 2008; Jagadeesan et al., 2013). 
In cluster analysis, the members within the cluster showed more similarity while between the clusters they showed more heterogeneity nature. Spatial and temporal similarity of species distribution of the observations from the Chavara transect (November 2013 and May 2014) were grouped into two clusters at 70\% similarity level (Fig. 3, 4). Cluster 1 included the observations of $10 \mathrm{~m}$ and $30 \mathrm{~m}$ locations of May 2014 and cluster 2 included the observations of $10 \mathrm{~m}$ and $30 \mathrm{~m}$ locations of November 2013. The grouping significance was tested in SIMPROF which showed that the grouping pattern was significant analysis $(P<0.01)$. Cluster 1 group members (stations at $10 \mathrm{~m}$ and $30 \mathrm{~m}$ during May) showed $47.42 \%$ similarity within observations. Labidocera pectinata, Centropages orsini, Labidocera acuta, Paracalanus parvus, Acartia erythraea, Centropages tenuiremis were the most important species in cluster 1. Among these, distribution of Labidocera pectinata and Centropages orsini showed more contribution to the similarity percentages such as $15.53 \%$ and $10.86 \%$ respectively. In cluster 2 , the important species were Paracalanus parvus, Centropages tenuiremis, Centropages orsini, Acartia danae, Acrocalanus gracilis, Oithona similis, Oithona spinirostris, Acartia erythraea and Pareucalanus attenuatus. Species distribution between the locations of $10 \mathrm{~m}$ and $30 \mathrm{~m}$ during November showed $60.32 \%$ similarity.

At Chavara station members of cluster one and two showed $77.37 \%$ dissimilarity. In these clusters, the distribution of following species were more dominant and altogether they contributed $90 \%$ to dissimilarity contribution such as Paracalanus parvus, Centropages tenuiremis, Temora turbinata, Centropages orsini, Acartia danae, Acrocalanus gracilis, Labidocera pectinata, Oithona similis, Oithona spinirostris, Labidocera acuta and Pareucalanus attenuatus. There was 2-3 folds variation in the abundances of Paracalanus parvus, Centropages tenuiremis, Temora turbinata, Centropages orsini, Acartia danae, Acrocalanus gracilis, Oithona similis, Oithona spinirostris and Pareucalanus attenuatus in cluster 2 locations. The abundances of Labidocera acuta, Centropages orsini and Labidocera pectinata were relatively high in the cluster 1 locations. The SIMPER (Similarity Percentage) analysis was performed along with the cluster mentioned above. This represents the similarity level within the cluster and their contributions of the species into that similarity level. Furthermore, it provides information about differences in similarity between the cluster and dominant members which one responsible for that dissimilarity. The results of SIMPER analysis is presented in Table 4. Table $4 \mathrm{a}$ and $4 \mathrm{~b}$ provide information about similarity percentage within the cluster members and the species contributed in each cluster. Table 4c shows information about dissimilarity between the two cluster groups and species contributions to that dissimilarity.

The relationships within and between the biological and environmental variables in Chavara transect during November 2013 and May 2014 were analysed by RDA (Fig. 5). In Redundancy Analysis, the triplot, exhibited that the relative directions of biological variable arrows had linear correlation among them. The arrows pointing in the opposite directions were predicted to have variables with a high negative correlation and arrows pointing in the same direction correspond to variables that are predicted to have a high positive correlation. In triplot, angle between the arrows of the environmental variables were useful to approximate the correlations among environmental variables in the scaling that are focused on biological correlations. Salinity and temperature oriented in the same direction indicating both were in a positive relationship to each other. The nitrate concentration in opposite direction indicated inverse relationship with temperature and salinity. The zooplankton density, chlorophyll a and species of Acartia danae, Acartia erythraea, Oithona similis, Oithona spinirostris, Oithona rigida, Centropages tenuiremis, Temora turbinata, Centropages orsini and Paracalanus parvus oriented to right hand direction which represents positive relationship to one another.

Low concentrations of nitrate, warm temperature and high salinity was found during May represented oligotrophic or low productivity in Chavara related to less production; cool, nutrient rich water column indicates upwelling signatures during November. Moreover, the upwelling indicator species Temora turbinata (Gowsami and Padmavati, 1996; Jagadeesan et al., 2013) was more abundant in the study, which indicated continuation or weakened upwelling of winter cooling during November. The distribution and abundance of copepods species alters the diversity pattern, when single species dominated to total density. The observation of increasing copepod species richness during spring intermonsoon was reported from inshore waters of Western Bay of Bengal (Rakesh et al., 2013). In the present study, the high species richness was found in the spring intermonsoon period compared to northeast monsoon period. It is concluded that there is a variation in the zooplankton abundance and copepod species diversity of Chavara Coast, due to the influence of seasonally varying hydrography of that environment.

\section{Acknowledgments}

The authors thank Scientist-in - charge, CSIR-National Institute of Oceanography, Regional Centre, Kochi, India for facilities and encouragement. We express our sincere thanks to Dr. R. Jyothibabu, Senior Scientist, CSIR-NIO, Regional Center, Kochi, India for his valuable suggestions and support. We thankfully acknowledge Head of the Department of Marine Biology, Microbiology and Biochemistry, Cochin University of Science and Technology, Cochin, India for providing the facilities. Authors wish to thank Ministry of Earth Science (MOES), Government of India for financial support through ITIS programme.

\section{References}

Abe, Y., M. Natsuike, K. Matsuno, T. Terui, A. Yamaguchi and I. Imai: Variation in assimilation efficiencies of dominant Neocalanus and Eucalanus copepods in the subarctic Pacific: Consequences for population structure models. J. Exp. Mar. Biol. Ecol., 449, 321-329 (2013).

Balqis, A.R.S., F. M. Yusoff, A. Arshad and J. Nishikawa: Seasonal 
variations of zooplankton biomass and size fractionated abundance in relation to environmental changes in a tropical mangrove estuary in the Straits of Malacca. J. Environ. Biol., 37, 685-695 (2016).

Clarke, K.R. and R.M. Warwick: Changes in marine communities: An approach to statistical analysis and interpretation. $2^{\text {nd }} E d n$., PRIMER-E Limited, Plymouth Marine Laboratory, United Kingdom, p.176(2001).

Clarke, K.R. and R.N. Gorley: PRIMER V6 : User Manual/Tutorial, PRIMER-E Limited, Plymouth Marine Laboratory, United Kingdom, p. 190 (2006).

Cleetus, RI., C.V. Asha, P.S. Suson and S.B. Nandan: Mesozooplankton abundance and community structure in vembanad-kol wetland ecosystem, Kerala, India. Indian J.Mar. Sci., 45, 533-545 (2016).

Conway, D.V.P., R. White, J. Hugues-Dit-Ciles, C. Gallienne and D. Robins: Guide to the coastal and surface zooplankton of the south western Indian Ocean. Occasional Publication No. 15. J. Mar. Biol. Assoc. U. K., p. 354 (2003)

Fernandes, V. and N. Ramaiah : Mesozooplankton community in the Bay of Bengal (India) : Spatial variability during the summer monsoon. Aquatic Ecol., 43, 951-963 (2009).

Gerson, V.J., N.V. Madhu, R. Jyothibabu, K.K. Balachandran, M. Nair and $\mathrm{C}$. Ravichandran: Oscillating environmental responses of the easternArabian Sea. Indian J. Mar. Sci., 43, 67-75 (2014).

Goswami, S.C. and G. Padmavati: Zooplankton production, composition and diversity in the coastal waters of Goa. Indian J. Mar. Sci., 25, 91-97 (1996).

Grasshoff, K., M. Ehrhardt and K. Kremling: Methods of seawater analysis. Verlag Chemie, Weinheim, pp. 89-224 (1983).

Hameed, T.S.S., N.P. Kurian, K.V. Thomas, K. Rajith and T.N. Prakash : Wave and current regime off the Southwest coast of India. J. Coast. Res., 23, 1167-1174 (2007).

Hsiao, S.H., S. Ka, T.H. Fang and J.S. Hwang: Zooplankton assemblages as indicators of seasonal changes in water masses in the boundary waters between the East China Sea and the Taiwan Strait. Hydrobiol., 666, 317 -330 (2011).

Hwang, J. and C.K. Wong : The China coastal current as a driving force for transporting Calanus sinicus (Copepoda Calanoida) from its population centers to waters of Taiwan and Hong Kong during the NE monsoon period in winter. J. Plankton Res., 27, 205-210 (2005).

Hwang, J., S. Souissi, L.C. Tseng, L. Seuront, F.G. Schmitt, L.S. Fang, S.H. Peng, C.H. Wu, S.H. Hsiao, W.H. Twan, T.P. Wei, R. Kumar, T.H. Fang, Q.C. Chen and C.K. Wong : A five - year study of the influence of the northeast and southwest monsoons on copepod assemblages in the boundary coastal waters between the East China Sea and the Taiwan Strait. J. Plankton Res., 28, 943-958 (2006).

Hwang, J., H. Dahms, L. Tseng and Q. Chen : Intrusions of the Kuroshio Current in the northern South China Sea affect copepod assemblages of the Luzon Strait. J. Exp. Mar. Biol. Ecol., 352, 1227 (2007).

Jagadeesan, L., R. Jyothibabu, A. Anjusha, P.M. Arya, N.V. Madhu, K.R. Muraleedharan and K. Sudheesh: Ocean currents structuring the mesozooplankton in the Gulf of Mannar and the Palk Bay, Southeast coast of India. Progr. Oceanogr., 110, 27-48 (2013).

Jeyaraj, N., S. Joseph, Arun, A. Suhaila, L. Divya and S. Ravikumar: Distribution and abundance of zooplankton in estuarine regions along the northern Kerala, Southwest coast of India. Ecologia, 4, 26-43 (2014).

Jyothibabu, R., N.V. Madhu, P.A. Maheswaran, K.V. Jayalakshmy, K.K.C. Nair and C.T. Achuthankutty: Seasonal variation of microzooplankton $(20-200 \mu \mathrm{m})$ and its possible implications on the vertical carbon flux in the western Bay of Bengal. Cont. Shelf. Res., 28, 737-755 (2008).

Kane, J.: Zooplankton abundance trends on Georges Bank, 1977 - 2004. ICES J. Mar. Sci., 64, 909-919 (2007).

Kasturirangan, L.: A key for the identification of the more common planktonic Copepoda of Indian coastal waters. Publication No .2, Indian National Committee on Oceanic Research., p.87 (1963).

Keister, J.E. and D. Bonnet : Zooplankton population connections, community dynamics and climate variability. ICES J. Mar. Sci., 69, $347-350$ (2012).

Keister, J.E. and L.B. Tuttle: Effects of bottom layer hypoxia on spatial distributions and community structure of mesozooplankton in a sub-estuary of Puget Sound, Washington, U.S.A. Limnol. Oceanogr., 58, 667-680 (2013).

Kobari, T., M. Moku and K. Takahashi: Seasonal appearance of expatriated boreal copepods in the Oyashio - Kuroshio mixed region. ICES J. Mar. Sci., 65, 469-476 (2008).

Madhupratap, M., S.R.S. Nair, P. Haridas and G. Padmavati: Response of zooplankton to physical changes in the environment: Coastal upwelling along the central west coast of India. J. Coast. Res., 6, 413-426 (1990).

Madhupratap, M., T.C. Gopalakrishnan, P. Haridas, K.K.C. Nair, P.N. Aravindakshan, G. Padmavati and S. Paul: Lack of seasonal and geographic variation in mesozooplankton biomass in the Arabian Sea and its structure in the mixed layer. Curr. Sci., 71, 863-868 (1996).

Madhupratap, M., T.C. Gopalakrishnan, P. Haridas and K.K.C. Nair: Mesozooplankton biomass, composition and distribution in the Arabian Sea during the Fall Intermonsoon: Implications of oxygen gradients. Deep-Sea Res. II., 48, 1345-1368 (2001).

Margalef, D.R.: Perspectives in ecological theory. University of Chicago Press, Chicago, p.111 (1968).

Muraleedharan, P.M. and S. Prasannakumar: Arabian Sea upwelling - A comparison between coastal and open ocean regions. Curr. Sci., 71, 842-846 (1996).

Naz, F., N.Z. Qureshi and N.U. Saher: Temporal and spatial variations in the species composition, distribution and abundance of copepods in mangrove creek area along the Karachi coast Pakistan. Indian J. Mar. Sci., 41, 61-69 (2012).

Perumal, N.V., M. Rajkumar, P. Perumal and K.T. Rajasekar: Seasonal variations of plankton diversity in the Kaduviyar estuary, Nagapattinam, southeast coast of India. J. Environ. Biol., 30, 1035 -1046 (2009).

Pielou, E.: Introduction to Mathematical Ecology. Wiley Interscience., p. 286 (1969).

Postel, L., H. Fock and W. Hagen: Biomass and abundance. Academic Press, ICES Zooplankton Methodology Manual,193-213 (2000).

Rajagopalan, M.S., P.A. Thomas, K.J. Mathew, G.S.D. Selvaraj, R.M. George, C.V. Mathew, T.S. Naomi, P. Kaladharan, V.K. Balachandran and G. Antony: Productivity of the Arabian Sea along the southwest coast of India. Bull. Central Marine Fish. Res. Inst., 45, 9-37 (1992).

Rajkumar, M., J. Suna, I.R. Jenkinsona and M.M. Rahmana: Seasonal variations in the structure of copepod assemblages in tropical marine and estuarine waters, Coleroon, south - east India. J. Mar. Biol.Assoc. U. K., 94, 521-535(2014).

Rakhesh, M., A.V. Raman and D. Sudarsan: Discriminating zooplankton assemblages in neritic and oceanic waters: A case for the Northeast coast of India, Bay of Bengal. Mar. Environ. Res., 61, 93-109 (2006).

Rakhesh, M., A.V. Raman, C. Kalavati, B.R. Subramanian, V.S. Sharma, E. Sunithababu and N. Sateesh: Zooplankton community 
structure across an eddy generated upwelling band close to a tropical bay - mangrove ecosystem. Mar. Biol., 154, 953-972 (2008).

Rakhesh, M., A.V. Raman, T. Ganesh, P. Chandramohan and F. Dehairs : Small copepods structuring mesozooplankton community dynamics in a tropical estuary -coastal system. Estuar. Coast. Mar. Sci., 126, 7-22 (2013).

Rao, D.S., C.P. Ramamirtham, A.V.S. Murty, S. Muthusamy, N.P. Kunhikrishnan and L.R. Khambadkar: Oceanography of the Arabian Sea with particular reference to the southwest monsoon. Bull. Central Marine Fish. Res. Inst., 45, 4-8 (1992).

Robin, R.S., M. Srinivasan and K. Chandrasekar: Distribution of zooplankton from Arabian Sea, along Southern Kerala (southwest coast of India) during the cruise Curr. Res. J. Biol. Sci., 1, 155-159 (2009).

Saher, M.H., F.J.C. Peeters and D. Kroon: Sea surface temperatures during the SW and NE monsoon seasons in the western Arabian Sea over the past 20,000 years. Palaeogeogr. Palaeoclimatol. Palaeoecol., 249, 216-228 (2007).

Santhanam, P., P. Perumal, S. Ananth and A.S. Devi : Copepod population in Vellar estuary, Parangipettai coast in relation to environmental conditions. J. Environ. Biol., 33, 1003-1010 (2012).

Sanu, V.F., S.B. Nandan, M.R. Raj and R. Radhika: Mesozooplankton distribution in Kavaratti Atoll, Lakshadweep Archipelago, Southwest coast of India with special reference to Calanoid copepods. IOSR J. Environ. Sci. Toxicol. Food Tech., 8, 69-78 (2014).

Sarangi, R.K.: Remote - sensing - based estimation of surface nitrate and its variability in the southern peninsular Indian waters. Int. J.
Oceanogr., doi : 10.1155/2011/172731.(2011).

Shannon, C.E. and W. Wiener: The Mathematical theory of communication. University of Illinois Press, Urbana, Illinois, p. 117 (1963).

Shenoi, S.S.C., D. Shankar, G.S. Michael, J. Kurian, K.K. Varma, M.R., Ramesh Kumar, A.M. Almeida, A.S. Unnikrishnan, W. Fernandes, N. Barreto, C. Gnanaseelan, R. Mathew, K.V. Praju and V. Mahale: Hydrography and water masses in the Southeastern Arabian Sea during March - June 2003. J. Earth. Syst. Sci., 114, 475-491 (2005).

Smith, S., M. Roman, I. Prusova, K. Wishner, M. Gowing, L.A. Codispoti, R. Barber, J. Marra and C. Flagg: Seasonal response of zooplankton to monsoonal reversal in the Arabian Sea. Deep Sea Res. II., 45, 2369-2403(1998).

Smitha, A., K.A. Joseph, C. Jayaram and A.N. Balchand: Upwelling in the Southeastern Arabian Sea as evidenced by Ekman mass transport using wind observations from OCEANSAT-II Scatterometer. Indian J. Mar. Sci., 43, 111-116 (2014).

Stephen, R., K.V. Jayalakshmy, K.R. Naveenkumar and V.R. Nair: Ecology and distribution of copepods from the Salt Pan Ecosystems of Mumbai, West Coast of India. J. Mar. Biol. Oceanogr., doi : 10.4172/2324-8661 (2013).

UNESCO : Protocols for the Joint Global Ocean Flux Study (JGOFS). Core Measurements, IOC Manuals and Guides. UNESCO, Paris, Vol. 29, p.170(1994).

Vineetha, G. N.V. Madhu, K.K. Kusum and P.M Sooria: Seasonal dynamics of the copepod community in a tropical monsoonal estuary and the role of sex ratio in their abundance pattern. Zool. Stud., 54, 1-19 (2015). 